\title{
GADD45A expression is correlated with patient prognosis in esophageal cancer
}

\author{
HIDEYUKI ISHIGURO, MASAHIRO KIMURA, HIROKI TAKAHASHI, TATSUYA TANAKA, \\ KOJI MIZOGUCHI and HIROMITSU TAKEYAMA \\ Department of Gastroenterological Surgery, Nagoya University Graduate School of Medical Science, \\ Nagoya, Aichi 467-8601, Japan
}

Received August 28, 2014; Accepted September 9, 2015

DOI: $10.3892 / \mathrm{ol} .2015 .3882$

\begin{abstract}
The prognosis of patients with esophageal cancer remains poor, and the tumor-node-metastasis classification system is not sufficient for predicting patient prognoses. Therefore, the identification of novel predictive markers for esophageal cancer is required. The present study investigated the clinicopathological significance of growth arrest and DNA damage-inducible $45 \alpha$ (GADD45A) and p53 in resectable esophageal squamous cell carcinoma (ESCC). The study consisted of 62 patients with esophageal cancer who underwent surgery between 2001 and 2007. The expression of the GADD45A gene product (GADD45A) and the p53 protein was analyzed by immunohistochemistry. The correlations among GADD45A expression, clinicopathological factors and prognosis were then analyzed in the patients with ESCC. GADD45A and p53 were expressed in 56.5\% (35/62) and 48.4\% (30/62) of patients, respectively. The expression of GADD45A did not show a marked correlation with that of p53. However, GADD45A expression correlated with pathological stage (stage 0-I vs. stages II-IV; $\mathrm{P}=0.014$ ) and did not correlate with the tumor $(\mathrm{T})$ or node $(\mathrm{N})$ status. Furthermore, patients who were positive for GADD45A exhibited a significantly higher survival rate than those who were negative for GADD45A (log-rank test, $\mathrm{P}=0.009)$. Multivariate analysis indicated that T status, $\mathrm{N}$ status and GADD45A expression were significant variables predicting survival (hazard ratio, 2.486; 95\% confidence interval, 1.168-5.290; $\mathrm{P}=0.018)$. Overall, GADD45A expression significantly affected the survival of patients with ESCC, and the reduced expression of GADD45A was correlated with a poor prognosis following curative surgery in these patients.
\end{abstract}

Correspondence to: Dr Hideyuki Ishiguro, Department of Gastroenterological Surgery, Nagoya University Graduate School of Medical Science, 1 Kawasumi, Mizuho-Cho, Mizuho-Ku, Nagoya, Aichi 467-8601, Japan

E-mail: h-ishi@med.nagoya-cu.ac.jp

Key words: GADD45A, p53, immunohistochemistry, prognosis, esophageal cancer

\section{Introduction}

The prognosis of esophageal cancer patients remains poor, emphasizing the requirement for the development of novel treatment strategies. At present, the overall 5-year survival rate is $<50 \%$, despite the use of multimodality therapies. Numerous patients, even those with early-stage disease, develop local recurrence of tumors or distant metastasis within a short time period after surgery. To develop novel treatment strategies, it is important to understand the biological behavior of esophageal cancer. Recent studies have found that a number of genes and molecules show involvement in the origin and/or progression of esophageal cancer, including tumor protein p53 (1), deleted in esophageal cancer 1 (2), deleted in colorectal cancer (3), deleted in lung cancer 1 (4), cyclin D1 (5), adenomatous polyposis coli (6) and survivin (7). However, the exact mechanisms underlying esophageal squamous cell carcinoma (ESCC) development and progression remain unclear.

The p53 gene is required for the proper induction of the $\mathrm{G}_{1}$ checkpoint and functions to upregulate growth arrest and DNA damage-inducible $45 \alpha(G A D D 45 A)$ and WAF1/p21 expression (8). Additionally, GADD45A is a downstream mediator of p53 and is able to deactivate p53, thereby contributing to cell cycle regulation through binding with cyclin-dependent kinases and proliferating cell nuclear antigen $(9,10)$. GADD45A stimulates DNA excision repair following cellular DNA damage (9). To the best of our knowledge, no studies have previously described the clinicopathological significance of GADD45A protein expression and its association with p53 protein in the progression of esophageal cancer.

Analysis of the immunoreactivity of p53 can be used as a measure of the loss of normal p53 function and the function of p53-related genes (11). These findings allow us to easily evaluate the status of the p53 gene by immunohistochemistry (11).

In the present study, the clinicopathological significance of GADD45A protein expression and its associations with the expression of its upstream mediator p53 were investigated in 62 patients with resectable ESCC.

\section{Materials and methods}

Tissue samples. Samples were obtained from 62 patients with ESCC who had undergone esophagectomy at the Department 
of Gastroenterological Surgery, Nagoya City University Graduate School of Medical Science (Nagoya, Aichi, Japan) between 1997 and 2005, without pre-operative chemotherapy or radiation. The tumors were classified according to the guidelines for clinical and pathological studies on carcinoma of the esophagus (12). The samples were used after obtaining written consent from the patients.

Immunohistochemistry. Immunohistochemical staining was then performed on the formalin-fixed, paraffin-embedded ESCC tissues using rabbit polyclonal anti-GADD45A (cat no. sc-792; Santa Cruz Biotechnology, Dallas, TX, USA) or mouse monoclonal anti-p53 (cat no. M7001; Dako, Glostrup, Denmark) antibodies at 1:200 and 1:75 dilutions, respectively. Paraffin-embedded sections $(4-\mu \mathrm{m})$ of tumors were deparaffinized, rehydrated, heat-treated by microwaving in $10 \mathrm{mM}$ citrate buffer for $15 \mathrm{~min}$ for antigen retrieval and cooled to room temperature. The sections were then treated with $0.3 \%$ $\mathrm{H}_{2} \mathrm{O}_{2}$ in methanol for 30 min to neutralize endogenous peroxidases, blocked with non-specific goat serum for $10 \mathrm{~min}$ and incubated with anti-GADD45A or anti-p53 overnight at room temperature in a humid chamber. Immunoreactive protein was detected with a DAKOEnvision system (horseradish peroxidase 3,3'-diaminobenzidine), and the sections were counterstained with hematoxylin. Immunostaining of GADD45A and p53 was subjectively assessed by two independent investigators, and discordant results were resolved by consultation with a third investigator. For the evaluation of GADD45A expression, immunostaining was considered positive only when unequivocally strong nuclear staining was present in $>50 \%$ of the tumor cells, as analyzed using a Olympus BX51 light microscope (Olympus corporation, Tokyo, Japan). Cases with only faint staining were regarded as negative. For evaluation of p53 expression, immunostaining was scored as positive only when the nucleus of the tumor cells was stained (13). According to previous studies, the cutoff point for $\mathrm{p} 53$ positivity was set as positive staining of $20 \%$ of the cells (13).

Statistical analysis. The $\chi^{2}$ test was used to compare the correlations between clinicopathological factors and the expression of GADD45A and p53. The cumulative survival rates were calculated according to the Kaplan-Meier method and compared by the Cox-Mantel test. Multivariate analysis of Cox's proportional hazard risk model was used to obtain the conditional risk of mortality due to ESCC. Statistical analysis was performed using the StatView software package (Abacus Concepts, Berkerly, CA, USA) Differences were considered statistically significant when $\mathrm{P}<0.05$.

\section{Results}

Expression of GADD45A and p53. First, the expression of GADD45A and p53 proteins in ESCC tissues was investigated by immunohistochemistry. Representative images of GADD45A and p53 immunostaining are shown in Figs. 1 and 2. Typical ESCC cells showed diffuse nuclear staining for GADD45A and p53, while the cell membrane and cytoplasm were not stained. Immunostaining for GADD45A and p53 was positive in $27.7 \%$ (13/47) and $46.8 \%$ (22/47) of patients, respectively. GADD45A and p53 were
Table I. Correlation of GADD45A immunohistochemistry results with clinicopathological factors, including patient and tumor characteristics, in esophageal cancer patients $(n=62)$.

\begin{tabular}{|c|c|c|c|}
\hline \multirow[b]{2}{*}{ Characteristic } & \multicolumn{2}{|c|}{ Expression, $\mathrm{n} /$ total $\mathrm{n}$} & \multirow[b]{2}{*}{ P-value } \\
\hline & ${\text { GADD } 45 \mathrm{~A}^{+}}^{-}$ & $\mathrm{p} 53^{+}$ & \\
\hline Age at surgery, years & & & 0.993 \\
\hline$<65$ & $22 / 39$ & $18 / 39$ & \\
\hline$>65$ & $13 / 23$ & $12 / 23$ & \\
\hline Gender & & & 0.952 \\
\hline Male & $27 / 48$ & $24 / 48$ & \\
\hline Female & $8 / 14$ & $6 / 14$ & \\
\hline Tumor status & & & 0.354 \\
\hline $\mathrm{T} 1$ & $7 / 9$ & $5 / 9$ & \\
\hline $\mathrm{T} 2$ & $4 / 7$ & $3 / 7$ & \\
\hline T3 & $15 / 25$ & $14 / 25$ & \\
\hline $\mathrm{T} 4$ & $9 / 21$ & $8 / 21$ & \\
\hline Lymph node status & & & 0.278 \\
\hline N0 & $7 / 9$ & $6 / 9$ & \\
\hline N1 & $5 / 10$ & $6 / 10$ & \\
\hline $\mathrm{N} 2$ & $11 / 23$ & $9 / 23$ & \\
\hline N3 & $5 / 11$ & $4 / 11$ & \\
\hline $\mathrm{N} 4$ & $7 / 9$ & $4 / 9$ & \\
\hline Pathological stage & & & 0.130 \\
\hline 0 & $2 / 2$ & $2 / 2$ & \\
\hline I & $5 / 5$ & $2 / 5$ & \\
\hline II & $2 / 6$ & $3 / 6$ & \\
\hline III & $12 / 23$ & $12 / 23$ & \\
\hline IV & $14 / 26$ & $10 / 26$ & \\
\hline 0-I vs. II-IV & & & 0.014 \\
\hline Histological differentiation & & & 0.364 \\
\hline Well & $14 / 25$ & $10 / 25$ & \\
\hline Moderate & $18 / 27$ & $14 / 27$ & \\
\hline Poor & $2 / 6$ & $3 / 6$ & \\
\hline Unknown & 4 & 4 & \\
\hline Lymphatic invasion & & & 0.696 \\
\hline Negative & $5 / 8$ & $5 / 8$ & \\
\hline Positive & $23 / 41$ & $22 / 41$ & \\
\hline Unknown & 13 & 13 & \\
\hline Blood vessel invasion & & & 0.634 \\
\hline Negative & $11 / 21$ & $13 / 21$ & \\
\hline Positive & $17 / 28$ & $14 / 28$ & \\
\hline Unknown & 13 & 13 & \\
\hline
\end{tabular}

GADD45A, growth arrest and DNA damage-inducible $45 \alpha$; T, tumor; $\mathrm{N}$, node.

expressed in 56.5\% (35/62) and 48.4\% (30/62) of esophageal cancer tissues, respectively (Table I). There were no correlations between the expression of GADD45A and that of p53 (data not shown). GADD45A expression was correlated significantly with pathological stage, but p53 expression did 


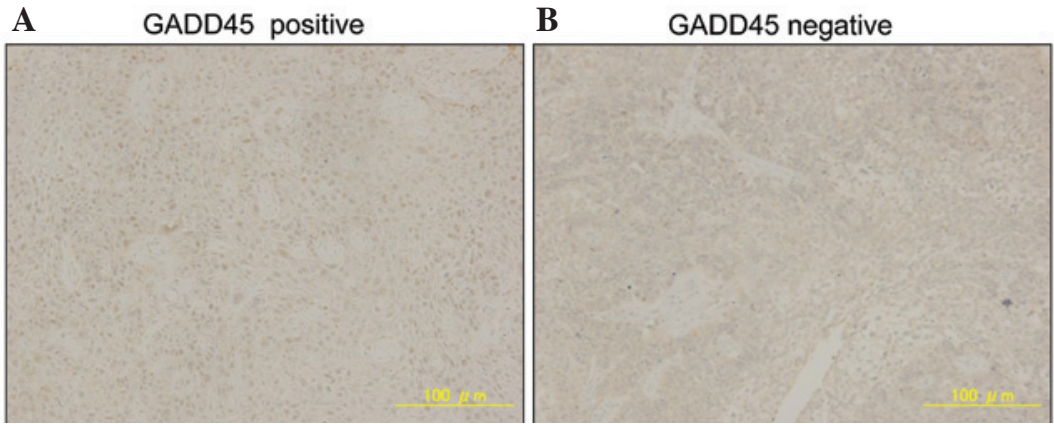

Figure 1. Representative immunostaining for GADD45A (x100 magnification). (A) Positive and (B) negative staining of GADD45A in tumor cells. GADD45A, growth arrest and DNA damage-inducible $45 \alpha$.

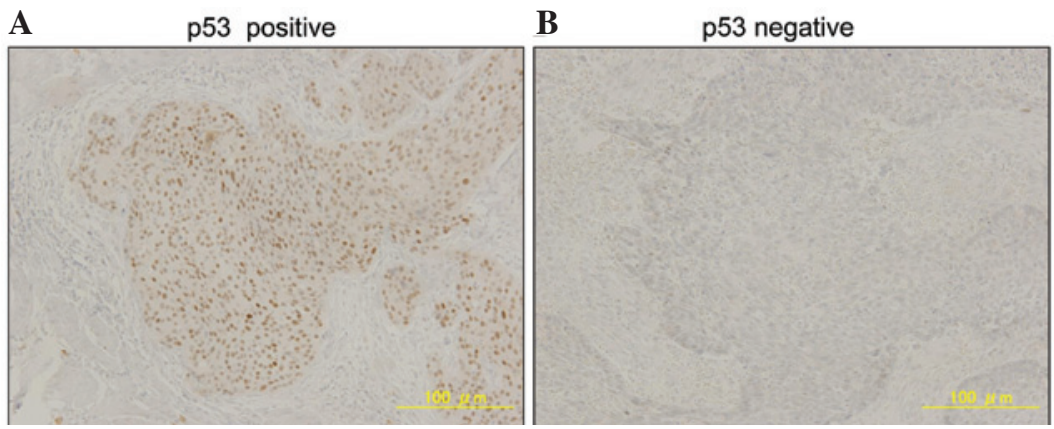

Figure 2. Representative immunostaining for p53 (x100 magnification). (A) Positive and (B) negative staining of p53 in the tumor cells.
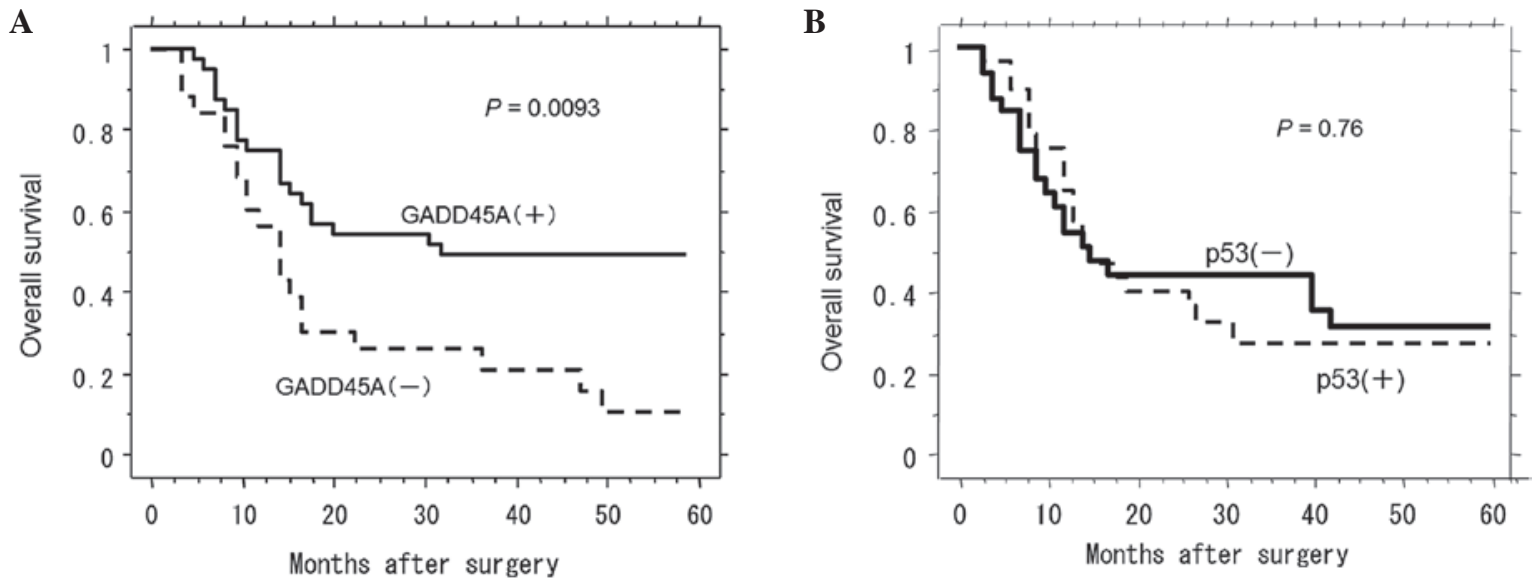

Figure 3. (A) Kaplan-Meier survival curve for esophageal cancer patients who were classified as showing either positive or negative GADD45A immunostaining. GADD45A status was found to be strongly associated (log-rank, $\mathrm{P}=0.0093$ ) with patient survival. (B) Kaplan-Meier survival curves for esophageal cancer patients who were classified as showing either positive or negative p53 immunostaining. p53 status did not show a significant (log-rank, $\mathrm{P}=0.76$ ) correlation with patient survival. GADD45A, growth arrest and DNA damage-inducible $45 \alpha$.

not correlate with any factors of the tumor-node-metastasis classification (Table I) (12).

Survival curves and the expression of GADD45A and p53. GADD45A exhibited a significant effect on patient survival (Fig. 3A). Indeed, the patients with positive staining for GADD45A experienced a significantly longer survival time following surgery compared with the patients with negative results $[27.0 \pm 1.3$ months $(n=35)$ vs. $12.0 \pm 1.2$ months $(n=27)$, respectively; $\mathrm{P}=0.0093$ by Log-rank test; Fig. 3A]. However, there were no significant differences in survival following surgery between patients with negative staining and patients with positive staining for $\mathrm{p} 53[15.0 \pm 3.9$ months $(\mathrm{n}=32)$ vs. $15.0 \pm 5.3$ months $(\mathrm{n}=30)$, respectively; $\mathrm{P}=0.76$ by Log-rank test; Fig. $3 \mathrm{~B}]$.

Next, the study investigated the correlation between immunostaining for GADD45A and the survival time of patients with ESCC following surgery (median follow-up time, 22.3 months). Univariate analysis showed that, among the clinicopathological factors examined, the extent of the primary tumor (risk ratio, 8.849; $\mathrm{P}<0.0001$ ), lymph node metastasis (risk ratio, 3.773; $\mathrm{P}<0.0001$ ), lymphatic invasion (risk ratio, 4.975; $\mathrm{P}<0.0001$ ), vein invasion (risk ratio, 2.906; 
Table II. Univariate analysis, including immunostaining for GADD45A.

\begin{tabular}{|c|c|c|c|}
\hline Parameter & Risk ratio & $95 \% \mathrm{CI}$ & P-value \\
\hline Age at surgery, years & & & 0.805 \\
\hline$<65$ & 1.000 & & \\
\hline$>65$ & 1.669 & $0.871-3.194$ & \\
\hline Gender & & & 0.866 \\
\hline Male & 1.000 & & \\
\hline Female & 0.956 & 0.097-.0435 & \\
\hline Primary tumor & & & $<0.0001$ \\
\hline $\mathrm{T} 1$ & 1.000 & & \\
\hline $\mathrm{T} 2-4$ & 8.849 & $4.081-19.230$ & \\
\hline Lymph node metastasis & & & $<0.0001$ \\
\hline N0-3 & 1.000 & & \\
\hline $\mathrm{N} 4$ & 3.773 & $2.386-5.952$ & \\
\hline Lymphatic invasion & & & $<0.0001$ \\
\hline Negative & 1.000 & & \\
\hline Positive & 4.975 & $2.283-10.869$ & \\
\hline Vein invasion & & & $<0.0001$ \\
\hline Negative & 1.000 & & \\
\hline Positive & 2.906 & $1.724-4.901$ & \\
\hline Immunostaining for GADD45A & & & 0.013 \\
\hline Positive & 1.000 & & \\
\hline Negative & 2.214 & $1.183-4.144$ & \\
\hline
\end{tabular}

CI, confidence interval; GADD45A, growth arrest and DNA damage-inducible 45 $\alpha$; T, tumor; N, node.

Table III. Multivariate analysis, including immunostaining for GADD45A.

\begin{tabular}{lcc}
\hline Parameter & Risk ratio & 95\% CI \\
\hline Primary tumor & & \\
T1 & 1.000 & $1.552-142.857$ \\
T2-4 & 15.384 & \\
Lymph node metastasis & & \\
N0-2 & 1.000 & $1.472-7.518$ \\
N3-4 & 3.333 & \\
Lymphatic invasion & & \\
Negative & 1.000 & $0.065-2.341$ \\
Positive & 0.391 & \\
Vein invasion & & 0.004 \\
Negative & 1.000 & $0.684-3.401$ \\
Positive & 1.524 & \\
Immunostaining for GADD45A & & $1.168-5.290$ \\
Positive & 1.000 & 0.302 \\
Negative & 2.486 & \\
\hline
\end{tabular}

CI, confidence interval; GADD45A, growth arrest and DNA damage-inducible 45 $\alpha$; , tumor; N, node.

$\mathrm{P}<0.0001$ ) and immunostaining for GADD45 (risk ratio, 2.214; $\mathrm{P}=0.013$ ) were statistically significant prognostic factors. By contrast, immunostaining for p53 was not a prognostic factor in univariate analysis (Table II). Multivariate analysis revealed that GADD45 expression was an independent prognostic factor (risk ratio, 2.486; $\mathrm{P}=0.0181$ ), 
together with the extent of the primary tumor (risk ratio, 15.384; $\mathrm{P}=0.0194$ ) and lymph node metastasis (risk ratio, 3.333; $\mathrm{P}=0.0038$ ) (Table III).

\section{Discussion}

DNA repair is central to human genome integrity. A reduced capacity for DNA repair has been associated with certain types of genetic susceptibility to cancer. GADD45A is involved in DNA replication and repair, and interacts with proliferating cell nuclear antigen (9). DNA excision repair is stimulated in vitro and the passage of cells into the $\mathrm{S}$ phase is inhibited by GADD45. Additionally, GADD45A is involved in the maintenance of the p53-dependent cell cycle checkpoint and DNA repair. In normal cells, GADD45 is localized to the nucleus (14). Consistent with this, the current experiments showed that GADD45A was expressed in the nucleus in ESCC cells. As GADD45A plays a role in genomic stability (15), additional studies will be necessary to assess whether GADD45A contributes to the growth of esophageal cancers.

The present study analyzed the expression of GADD45A and $\mathrm{p} 53$ by immunohistochemistry. The mutant $\mathrm{p} 53$ protein is more stable than the wild-type protein and can be detected by immunohistology (16). The immunoreactivity of p53 can be used as a measure of the loss of normal p53 function (13). Therefore, the overexpression of $\mathrm{p} 53$ by immunohistochemistry may indicate mutant $\mathrm{p} 53$. While the present results suggested that p53 did not contribute to patient prognosis, controversy remains over whether p53 expression is a good prognostic marker in esophageal cancer $(17,18)$. The present data suggested that the aberrant expression of p53 was not correlated with patient prognosis in esophageal cancer.

GADD45A is a downstream target of p53 signaling (19-21). However, as few studies have described the mechanisms mediating GADD45A expression in ESCC, it is not known whether p53 regulates GADD45A expression in this cancer type (22). Notably, the present study found that GADD45A, but not p53, was able to predict the prognosis of patients with ESCC. Thus, the data suggested that p53 is involved in the carcinogenesis of esophageal cancer and that GADD45A could be a useful biomarker for predicting prognosis in patients with ESCC. However, the expression of GADD45A was not markedly correlated with that of $\mathrm{p} 53$. Thus, the mechanism behind the regulation of GADD45A expression in ESCC remains unclear. Other factors, such as myc, phosphoinositide 3-kinase/AKT $(23,24)$, activating transcription factor 2 (25) and Quercetin (26), which have been shown to regulate GADD45A expression, should be investigated in future studies.

A number of studies have shown that GADD45A functions to repair DNA damage under normal p53 signaling (27-29). On the other hand, more recent studies have demonstrated that there is no significant correlation between p53 status and basal GADD45A expression in tumor cells $(13,14,30)$. The present study data also showed that GADD45A expression was not correlated with p53 status. Accordingly, the correlation between p53 status and GADD45A expression remains unclear and should be clarified in future studies.

Certain clinical studies have indicated that the expression of GADD45 is an indicator of a poor prognosis or malignant potential in cervical carcinomas (31), lung cancer (32) and gastric cancer (33). Moreover, the combined evaluation of thymidine phosphorylase and GADD45 gene expression can predict therapeutic response in adenocarcinomas of the upper gastrointestinal tract (34). On the other hand, GADD45 mRNA levels may not be useful for the prediction of the neoadjuvant chemotherapy success in individual cancer patients with locally advanced Barrett adenocarcinoma (35). The current study may be the first to demonstrate that GADD45A is an independent prognostic factor in esophageal cancer.

In the present study, it was found that decreased GADD45A expression in the cancer tissues accompanied the local progression of esophageal cancer (Fig. 1 and Table II). In addition, patients with lower GADD45A expression levels had a poorer prognosis (Fig. 2). Further studies are required to determine how deficiencies in DNA repair resulting from downregulation of GADD45A may promote tumor progression and lead to poor prognoses in patients with ESCC.

The GADD 45A gene is localized to human chromosome 1 between p12 and $\mathrm{p} 34$ (36). A number of studies have suggested that the GADD45A locus (1p) may harbor tumor-suppressor genes for glioma (37), lung cancer (38) and gastric cancer (39). Therefore, loss of GADD45A may also contribute to the development of numerous other types of cancer. Further studies are required to determine whether there were chromosomal losses in the GADD45A locus in the esophageal tumor tissues examined in the present study. Additionally, determining whether GADD $45 A$ expression is mediated by other mechanisms, such as methylation of the promoter region, will be the focus of future studies.

In patients with esophageal cancer, numerous prognostic markers, including cyclin D1, E-cadherin and MDM2 proto-oncogene, E3 ubiquitin protein ligase, have been reported $(40,41)$. Furthermore, we have also previously reported that survivin (7), pituitary tumor-transforming gene 1 (42), DNA fragmentation factor 45 (43) and drosha, ribonuclease type III (44) may be prognostic markers of ESCC. Thus, GADD45A represents an additional potential prognostic indicator for patients with ESCC.

Although the precise molecular mechanisms through which GADD45A is downregulated require clarification, the present study data clearly indicated that GADD45A may be a prognostic marker and molecular target for the development of effective therapeutic reagents for patients with esophageal cancer.

\section{Acknowledgements}

The authors would like to thank Ms. Seiko Inumaru and Ms.YumikaAsano(Department of GastroenterologicalSurgery, Nagoya University Graduate School of Medical Science, Nagoya, Japan) for providing excellent technical assistance.

\section{References}

1. Robert V, Michel P, Flaman JM,et al: High frequency in esophageal cancers of $\mathrm{p} 53$ alterations inactivating the regulation of genes involved in cell cycle and apoptosis. Carcinogenesis 21: 563-565, 2000.

2. Nishiwaki T, Daigo Y, Kawasoe T and Nakamura Y: Isolation and mutational analysis of a novel human cDNA, DEC1 (deleted in esophageal cancer 1), derived from the tumor suppressor locus in 9q32. Genes Chromosomes Cancer 27: 169-176, 2000.

3. Miyake S, Nagai K, Yoshino K, Oto M, Endo M and Yuasa Y: Point mutations and allelic deletion of tumor suppressor gene DCC in human esophageal squamous cell carcinomas and their relation to metastasis. Cancer Res 54: 3007-3010, 1994. 
4. Daigo Y, Nishiwaki T, Kawasoe T, et al: Molecular cloning of a candidate tumor suppressor gene, DLC1, from chromosome 3p21.3. Cancer Res 59: 1966-1972, 1999.

5. Jiang W, Zhang YJ, Kahn SM, et al: Altered expression of the cyclin D1 and retinoblastoma genes in human esophageal cancer. Proc Natl Acad Sci USA 90: 9026-9030, 1993.

6. Boynton RF, Blount PL, Yin J, et al: Loss of heterozygosity involving the APC and MCC genetic loci occurs in the majority of human esophageal cancers. Proc Natl Acad Sci USA 89: 3385-3388, 1992.

7. Kato J, Kuwabara Y, Mitani M, et al: Expression of survivin in esophageal cancer: Correlation with the prognosis and response to chemotherapy. Int J Cancer 95: 92-95, 2001.

8. Kastan MB,Zhan Q, el-Deiry WS, et al: A mammalian cell cycle checkpoint pathway utilizing p53 and GADD45 is defective in ataxia-telangiectasia. Cell 71: 587-597, 1992.

9. Smith ML, Chen IT, Zhan Q, et al: Interaction of the p53-regulated protein Gadd45 with proliferating cell nuclear antigen. Science 266: 1376-1380, 1994.

10. Marx J: New link found between p53 and DNA repair. Science 266: 1321-1322, 1994.

11. McGregor JM, Yu CC, Dublin EA, et al: Aberrant expression of p53 tumour-suppressor protein in non-melanoma skin cancer. $\mathrm{Br}$ J Dermatol 127: 463-469, 1992.

12. Japan Esophageal Society: Japanese Classification Esophageal Cancer, Tenth Edition: Part 1. Esophagus 6: 1-25, 2009.

13. Yamasawa K, Nio Y, Dong M, Yamaguchi K and Itakura M: Clinicopathological significance of abnormalities in Gadd45 expression and its relationship to $\mathrm{p} 53$ in human pancreatic cancer. Clin Cancer Res 8: 2563-2569, 2002.

14. Carrier F, Bae I, Smith ML, Ayers DM and Fornace AJ Jr: Characterization of the GADD45 response to ionizing radiation in WI-L2-NS cells, a 53 mutant cell line. Mutat Res 352: 79-86, 1996.

15. Hollander MC, Sheikh MS, Bulavin DV, et al: Genomic instability in Gadd45a-deficient mice. Nat Genet 23: 176-184, 1999.

16. Shurbaji MS, Kalbfleisch JH and Thurmond TS Immunohistochemical detection of p53 protein as a prognostic indicator in prostate cancer. Hum Pathol 26: 106-109, 1995.

17. Yen CC, Tsao YP, Chen PC, et al: PML protein as a prognostic molecular marker for patients with esophageal squamous cell carcinomas receiving primary surgery. J Surg Oncol 103 761-767, 2011.

18. Liu WK, Jiang XY, Zhang MP and Zhang ZX: The relationship between HPV16 and expression of cyclooxygenase-2, P53 and their prognostic roles in esophageal squamous cell carcinoma. Eur J Gastroenterol Hepatol 22: 67-74, 2010.

19. Vikhanskaya F, Lee MK, Mazzoletti M, et al: Cancer-derived p53 mutants suppress p53-target gene expression-potential mechanism for gain of function of mutant p53. Nucleic Acids Res 35: 2093-2104, 2007.

20. Jackson JG and Pereira-Smith OM: p53 is preferentially recruited to the promoters of growth arrest genes p21 and GADD45 during replicative senescence of normal human fibroblasts. Cancer Res 66: 8356-8360, 2006.

21. Butz K, Whitaker N, Denk C, et al: Induction of the p53-target gene GADD45 in HPV-positive cancer cells. Oncogene 18: 2381-2386, 1999.

22. Wang B, Yin BL, He B, et al: Overexpression of DNA damageinduced 45 alpha gene contributes to esophageal squamous cel cancer by promoter hypomethylation. J Exp Clin Cancer Res 31: 11,2012

23. Amente S, Zhang J, Lavadera ML, Lania L, Avvedimento EV and Majello B: Myc and PI3K/AKT signaling cooperatively repress FOXO3a-dependent PUMA and GADD45a gene expression. Nucleic Acids Res 39: 9498-9507, 2011.

24. Zhu QS, Ren W, Korchin B, et al: Soft tissue sarcoma cells are highly sensitive to AKT blockade: A role for p53-independent up-regulation of GADD45 alpha. Cancer Res 68: 2895-2903, 2008

25. Maekawa T, Sano Y, Shinagawa T, et al: ATF-2 controls transcription of Maspin and GADD45 alpha genes independently from p53 to suppress mammary tumors. Oncogene 27: 1045-1054, 2008.

26. Yoshida T, Maeda A, Horinaka M, et al: Quercetin induces gadd45 expression through a p53-independent pathway. Oncol Rep 14: 1299-1303, 2005

27. Kuerbitz SJ, Plunkett BS, Walsh WV and Kastan MB: Wild-type p53 is a cell cycle checkpoint determinant following irradiation. Proc Natl Acad Sci USA 89: 7491-7495, 1992.
28. Maity A, McKenna WG and Muschel RJ: The molecular basis for cell cycle delays following ionizing radiation: A review. Radiother Oncol 31: 1-13, 1994

29. Wang XW, Zhan Q, Coursen JD, Khan MA, Kontny HU, Yu L, Hollander MC, O'Connor PM, Fornace AJ Jr and Harris CC: GADD45 induction of a G2/M cell cycle checkpoint. Proc Natl Acad Sci USA 96: 3706-3711, 1999.

30. Amundson SA, Myers TG, Scudiero D, Kitada S, Reed JC and Fornace AJ Jr: An informatics approach identifying markers of chemosensitivity in human cancer cell lines. Cancer Res 60: 6101-6110, 2000

31. Santucci MA, Barbieri E, Frezza G, Perrone A, Iacurti E, Galuppi A, Salvi F, Bunkeila F, Neri S, Putti C, et al: Radiation-induced gadd45 expression correlates with clinical response to radiotherapy of cervical carcinoma. Int J Radiat Oncol Biol Phys 46: 411-416, 2000.

32. Harkin DP, Bean JM, Miklos D, Song YH, Truong VB, Englert C, Christians FC, Ellisen LW, Maheswaran S, Oliner JD, et al: Induction of GADD45 and JNK/SAPK-dependent apoptosis following inducible expression of BRCA1. Cell 97: 575-586, 1999.

33. Guo W, Dong Z, Guo Y, Chen Z, Kuang G and Yang Z: Methylation-mediated repression of GADD45A and GADD45G expression in gastric cardia adenocarcinoma. Int J Cancer 133: 2043-2053, 2013

34. Hofler H, Langer R, Ott K and Keller G: Prediction of response to neoadjuvant chemotherapy in carcinomas of the upper gastrointestinal tract. Recent Results Cancer Res 176: 33-36, 2007.

35. Langer R, Specht K, Becker K, Ewald P, Bekesch M, Sarbia M, Busch R, Feith M, Stein HJ, Siewert JR, et al: Association of pretherapeutic expression of chemotherapy-related genes with response to neoadjuvant chemotherapy in Barrett carcinoma. Clin Cancer Res 11: 7462-7469, 2005.

36. Papathanasiou MA, Kerr NC, Robbins JH, McBride OW, Alamo I Jr, Barrett SF, Hickson ID and Fornace AJ Jr: Induction by ionizing radiation of the gadd 45 gene in cultured human cells: Lack of mediation by protein kinase C. Mol Cell Biol 11: 1009-1016, 1991

37. Barbashina V, Salazar P, Holland EC, Rosenblum MK and Ladanyi M: Allelic losses at 1p36 and 19q13 in gliomas: Correlation with histologic classification, definition of a $150-\mathrm{kb}$ minimal deleted region on $1 \mathrm{p} 36$ and evaluation of CAMTA1 as a candidate tumor suppressor gene. Clin Cancer Res 11: 1119-1128, 2005.

38. Girard L, Zöchbauer-Müller S, Virmani AK, Gazdar AF and Minna JD: Genome-wide allelotyping of lung cancer identifies new regions of allelic loss, differences between small cell lung cancer and non-small cell lung cancer and loci clustering. Cancer Res 60: 4894-4906, 2000.

39. Igarashi J, Nimura Y, Fujimori M, Mihara M, Adachi W, Kageyama H and Nakagawara A: Allelic loss of the region of chromosome 1p35-pter is associated with progression of human gastric carcinoma. Jpn J Cancer Res 91: 797-801, 2000.

40. Itami A, Shimada Y, Watanabe G and Imamura M: Prognostic value of p27 (Kip1) and CyclinD1 expression in esophageal cancer. Oncology 57: 311-317, 1999.

41. Shimada Y, Imamura M, Shibagaki I, Tanaka H, Miyahara T, Kato $\mathrm{M}$ and Ishizaki K: Genetic alterations in patients with esophageal cancer with short- and long-term survival rates after curative esophagectomy. Ann Surg 226: 162-168, 1997.

42. Shibata Y, Haruki N, Kuwabara Y, Nishiwaki T, Kato J, Shinoda N, Sato A, Kimura M, Koyama H, Toyama T, et al: Expression of PTTG (pituitary tumor transforming gene) in esophageal cancer. Jpn J Clin Oncol 32: 233-237, 2002.

43. Konishi S, Ishiguro H, Shibata Y, Kudo J, Terashita Y, Sugiura H, Koyama H, Kimura M, Sato A, Shinoda N, et al: Decreased expression of DFF45/ICAD is correlated with a poor prognosis in patients with esophageal carcinoma. Cancer 95: 2473-2478, 2002.

44. Sugito N, Ishiguro H, Kuwabara Y, Kimura M, Mitsui A, Kurehara H, Ando T, Mori R, Takashima N, Ogawa R, et al: RNASEN regulates cell proliferation and affects survival in esophageal cancer patients. Clin Cancer Res 12: 7322-7328, 2006. 